\title{
Effects of polyaromatic hydrocarbons on the forest ecosystem and woody plants
}

\author{
M. Berteigne ${ }^{1}$, C. Rose ${ }^{1}$, J. Gérard² and P. Dizengremel ${ }^{2}$ \\ 1 Laboratoire d'Etude de la Pollution Atmosphérique, INRA-CRF, Champenoux, 54280 Seichamps, \\ and \\ 2Laboratoire de Physiologie Végétale et Forestière, Université Nancy I, BP 239, 54506 \\ Vandœuvre, France
}

\section{Introduction}

Polyaromatic hydrocarbons (PAH) are known to be animal carcinogens and/or bacterial mutagens. The few studies conducted on the effects of PAH on plant physiology describe them as hormone-like compounds. Carrot callus differentiation is obtained with the carcinogen benzo(a)pyrene (BaP) (Levine, 1951). The direct application of a nutrient solution containing $10 \mathrm{ppb} \mathrm{BaP}$ to tobacco plantlets induces a $100 \%$ growth-promoting effect (Graf and Nowak, 1966). Graf and Diehl (1966) reported a 3-5-fold increase in endogenous PAH content during leaf yellowing. PAH are therefore assumed to be associated with plant senescence and chlorophyll degradation and could be considered as a new kind of senescenceinducing hormone. The problem of the presence in the atmosphere of organic pollutants of anthropogenic origin was recently raised (Krause, 1987) and their possible effect on higher plant physiology has to be questioned, since they can be transported to remote areas (Matzner, 1984). In this paper, the levels of PAH in soil and trees of the Vosges mountains were evaluated. Simulation experiments were also undertaken to estimate the $\mathrm{PAH}$ toxicity for plant cell metabolism.

\section{Methods for extraction and analysis of PAH}

Oven-dried samples $\left(5 \mathrm{~d}\right.$ at $\left.50^{\circ} \mathrm{C}\right)$ were extracted with cyclohexane $(6 \mathrm{~h})$ and purified using Sephadex LH 20/isopropanol preparative chromatography. The dried extracts (containing standard naphthalene in cyclohexane) were analyzed by gas chromatography and each $\mathrm{PAH}$ was qualitatively determined by mass spectrometry.

\section{Results}

PAH load in Vosgian soil

The upper organic layers $L, F$ and $H$ and the organo-mineral $A_{1}$ layer of Vosgian soil were analyzed to determine their spe- 
cific PAH contamination. An accumulation process was found to occur in the $\mathrm{H}$ layer. The fluoranthene contents of the $L, F, H$ layers increased, respectively, from 70 $\mathrm{ppb}$ to $200 \mathrm{ppb}$ and $540 \mathrm{ppb}$, and then decreased to $80 \mathrm{ppb}$ in the $A_{1}$ layer. Since endogenous $\mathrm{PAH}$ are known not to exceed a few $\mathrm{ppb}$, the reported values indicate an important anthropogenic contribution to soil contamination. The accumulation rates (defined as the ratio: $\mathrm{PAH}$ in the $\mathrm{H}$ layer/PAH in the $\mathrm{L}$ layer), ranging from 3.5 for phenanthrene to 7.5 for benzo(a)pyrene, were found to be linked to their molecular weights. This suggests that PAH physical properties (solubility, adsorption process) are the rate-limiting factors governing $\mathrm{PAH}$ fate in the upper soil layers. However, benzofluoranthenes were an exception to this rule, since they showed a low accumulation rate (5.5) in comparison to what could be expected from their high molecular weight and their low water solubility $(<4$ $\mu \mathrm{g} / \mathrm{l})$. As benzofluoranthenes are molecules with a 5 carbon ring (less stable than an aromatic ring), this particular accumulation feature suggests chemical reactivity to be an additional factor governing PAH fate in the soil. PAH accumulation in the forest ecosystem is thus under both physical and chemical controls. The chemical process leads to the hypothesis that interactions between PAH and microorganisms and/or trees must be taken into account.

\section{Seasonal PAH changes in spruce tissues}

The content in $3 \mathrm{PAH}$ (phenanthrene, fluoranthene and pyrene) was measured in diseased (yellowing) and healthy spruce trees. Spruce needles and roots were sampled each month from mid-June to mid-September.

In June, the PAH in tissues from damaged spruce trees was about $100 \mathrm{ppb}$ in the needles and $120 \mathrm{ppb}$ in the roots, whereas these values were, respectively, 40 and $30 \mathrm{ppb}$ for healthy trees. The PAH content decreased throughout the summer to a few ppb before increasing once more in early autumn. This seasonal variation points out that $\mathrm{PAH}$ removal could be under the control of a photochemicalenhanced catabolism. The differences observed in June between healthy and diseased trees suggest that this lightdependent detoxification process could be disturbed in the latter group.

\section{PAH effects on spruce seedlings}

Spruce seeds were sown under sterile conditions $\left(\mathrm{H}_{2} \mathrm{O}_{2}, \mathrm{MeOH}\right)$. Once their roots had germinated, they were transplanted into culture tubes containing nutritive woody plant medium (WPM) (Smith and McCown, 1983). Four weeks later, 14 seedlings were transplanted into $\mathrm{PAH}$ containing WPM, 14 control seedlings were transplarited into WPM alone. From the beginning of the experiment up to the 5 th $w \mathrm{k}$, seedlings were grown under low light intensity $\left(1.2 \mathrm{~W} \cdot \mathrm{m}^{-2}\right)$ and were thereafter subjected to a higher luminosity $(20$ $\left.W \cdot m^{-2}\right)$. The PAH used in this simulation experiment were phenanthrene (39 nmol/ plant), fluoranthene (134 nmol/plant) and pyrene (99 nmol/plant). These amounts correspond to 3 -fold the contamination of the $\mathrm{H}$ layer in Vosgian soil. Seedlings were sampled on diays $12,19,28,35,44,49$ and 54 after the beginning of the experiment. Amino acids, free sugars and proteins were analyzed in response to the treatment.

Visual necrosis only occurred after day 41 following light exposure. Necrosis was characterized by needle tip yellowing and a further spread of this yellowing to the whole needle. The needles formed during the simulation experiment were not affect- 
ed by the treatment. Needle and root growth were inhibited by $\mathrm{PAH}$.

Metabolites responded as early as day 12. Methionine, proline and phenylalanine were found to be the amino acids indicating PAH stress. Methionine and proline levels remained high in the $\mathrm{PAH}$-treated seedlings throughout the experiment, whereas phenylalanine content increased only after the higher light exposure. Fructose and glucose levels were higher in the $\mathrm{PAH}$-treated seedlings at the beginning of the experiment (days 12 and 19). The amount of protein initially decreased drastically in the PAH-treated spruces. Following high light exposure, the protein level increased in the PAH-treated seedlings at a rate 2 -fold higher than in control seedlings.

\section{PAH effect on isolated mitochondria}

The effects of PAH and their relative oxidation products were studied on mitochondria isolated from green and non-green tissues from different plants. The action of these compounds was investigated during mitochondrial succinate oxidation. Studies on potato tuber mitochondria showed that $\mathrm{PAH}$ were more active respiratory inhibi- tors than the corresponding oxidation products. The effects of phenanthrene, fluoranthene, pyrene, benz(a)anthracene, BaP and benzofluoranthenes were investigated on mitochondria isolated from Agaricus bisporus. The most effective inhibitors were the low molecular weight PAH. The pattern of inhibition of the phosphorylating state 3 rate was found to be clearly nonlinear, as previously observed (Dizengremel and Citerne, 1988). Studies of the effects of phenanthrene, fluoranthene and pyrene were made on lupin mitochondria. Fig. 1 shows the effects of fluoranthene on lupin root and green cotyledon mitochondria. Generally, the respiration was halfinhibited with $5 \times 10^{-5} \mathrm{M}$ for root mitochondria and $2 \times 10^{-4} M$ for green tissue mitochondria, which thus appeared to be less affected by PAH.

\section{Conclusion}

On the basis of this preliminary work, low molecular weight PAH (phenanthrene, fluoranthene and pyrene) can be considered to strongly affect physiological mechanisms in higher plants. Further research is needed to fully understand their mode of

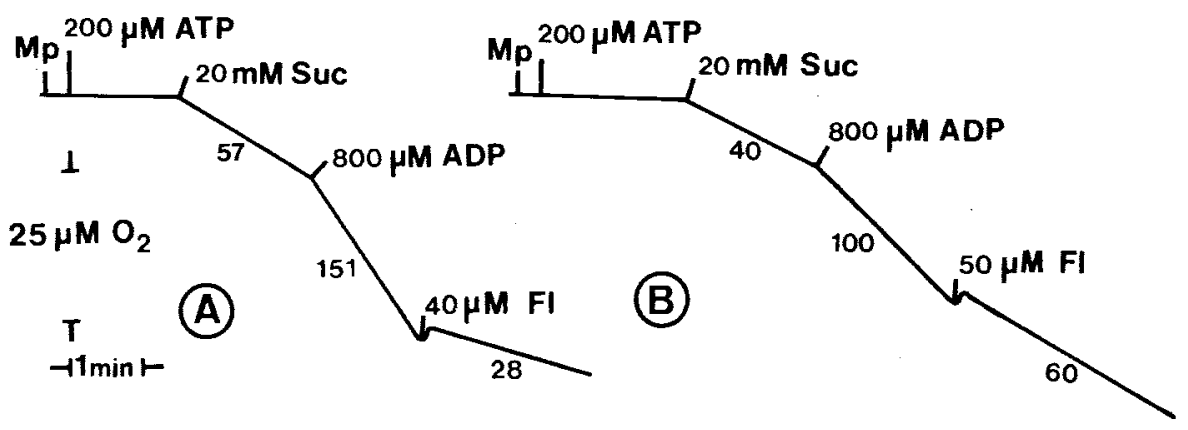

Fig. 1. Effect of fluoranthene (F) on the oxidation of succinate (Suc) by lupin root (A) and green cotyledon (B) mitochondria. Values along the tracings are in $\mathrm{nmol}$ of $\mathrm{O}_{2} \cdot \mathrm{min}^{-1} \cdot \mathrm{mg}^{-1}$ protein. 
action. PAH activity could result from their similarity to senescence hormones. Soil pollution by $\mathrm{PAH}$ could create an imbalance in the forest ecosystem leading to severe damage. However, the question arises whether the $\mathrm{PAH}$-induced yellowing of spruce needles could be related to that frequently observed in the field and generally thought to be due to $\mathrm{Mg}$-deficiency.

\section{References}

Dizengremel P. \& Citerne A. (1988) Air pollutant effects on mitochondria and respiration. In: Air Pollution and Plant Metabolism. (Schulte-Hostede S., Darall N.M., Blank L.W. \& Wellburn A.R., eds.), Elsevier Applied Science, London, pp. 169-188

Graf W. \& Diehl H. (1966) Concerning the naturally caused normal level of carcinogenic poly- cyclic aromatics. Arch. Hyg. Bakteriol. 150, 4959

Graf W. \& Nowak W. (1966) Promotion of growth in lower and higher plants by carcinogenic polycyclic aromatics. Arch. Hyg. Bacteriol. $150,513-518$

Krause G.H.M. (1987) Forest decline and the role of air pollutants. In: Acid Rain: Scientific and Technical Advances. (Perry R., Harrison R.M., Bell J.N.B3. \& Lester J.N., eds.), Selper Ltd., London, pp. 621-632

Levine M. (1951) The effects of growth substances and chemical carcinogens on fibrous roots of carrot tissue grown in vitro. Am. J. Bot. 38, 132-138

Matzner E. (1984) Annual rates of deposition of polycyclic aromatic hydrocarbons in long-range transported aerosols. Water Air Soil Pollut. 21, 425-434

Smith M.A.L. \& McCown B.H. (1983) A comparison of source tissue for protoplast isolation from three woody plant species. Plant Sci. Lett. $28,149-156$ 